\title{
CLONAGEM, EXPRESSÃO E CARACTERIZAÇÃO DA NUCLEOPROTEÍNA RECOMBINANTE DO VÍRUS DA BRONQUITE INFECCIOSA EM ESCHERICHIA COLI E EM PICHIA PASTORIS
}

\section{A.M. Gibertoni, M.C.M. Gonçalves, M.F.S. Montassier, C.C. Fernandes, H.J. Montassier}

Universidade Estadual Paulista, Faculdade de Ciências Agrárias e Veterinárias, Departamento de Patologia Veterinária, Laboratório de Virologia e Imunologia, Via de acesso Prof. Paulo Donatto Castellane, s/nº , CEP 14884-900, Jaboticabal, SP, Brasil. E-mail: aligiber@zipmail.com.br

\section{RESUMO}

O gene da proteína de nucleocapsídeo (1.230 pb) da estirpe M41 do vírus da bronquite infecciosa (VBI) foi amplificado pelas reações de transcrição reversa e em cadeia da polimerase (RT-PCR) e clonado, em seguida, em dois sistemas; pET28a - Escherichia coli e pFLD - Pichia pastoris. Os produtos recombinantes construídos para expressão (pET28a-N ou pFLD-N) foram identificados por análises de PCR e de sequenciamento de nucleotídeos. Os clones transformantes da linhagem BL21 de E. coli e da linhagem GS115 de P. pastoris foram submetidos aos protocolos apropriados de indução. A expressão da proteína $\mathrm{N}$ de fusão com etiqueta de poli-histidina e com massa molecular de $54 \mathrm{kDa}$ foi determinada pelas técnicas de SDS-PAGE e de Western blotting, confirmando-se que ambas proteínas $\mathrm{N}$ recombinantes apresentaram tamanhos e antigenicidade compatíveis com a proteína N nativa do próprio VBI. O sistema E. coli expressou uma quantidade relevante da proteína N recombinante, enquanto que o sistema $P$. pastoris produziu uma baixa recuperação dessa proteína recombinante. A proteína $\mathrm{N}$ recombinante gerada pelo sistema bacteriano foi purificada em resina de níquel-sepharose. O conjunto de resultados indica que o sistema de expressão constituído por pET28a - E. coli é mais efetivo para produzir a proteína N recombinante do VBI destinada ao uso como antígeno para detectar anticorpos anti-virais específicos em ensaios de imunodiagnóstico para essa infecção viral.

PALAVRAS-CHAVE: Vírus da Bronquite Infecciosa, clonagem, expressão, antígeno recombinante, ELISA.

\section{ABSTRACT}

CLONING, EXPRESSION, ANDCHARACTERIZATIONOFTHENUCLEOCAPSIDPROTEIN OF INFECTIOUS BRONCHITIS VIRUS IN ESCHERICHIA COLI AND PICHIA PASTORIS. The nucleocapsid protein $(\mathrm{N})$ gene $(1,230 \mathrm{bp})$ of the M41 strain of infectious bronchitis virus (IBV) was amplified by reverse transcriptase-polymerase chain reaction (RT-PCR), and cloned in two systems; pET28a Escherichia coli and pFLD Pichia pastoris. The recombinant expression constructs ( $\mathrm{pET} 28 \mathrm{a}-\mathrm{N}$ or pFLD-N) were identified by PCR and sequencing analysis. The transformant clones of BL21 strain of E. coli or GS115 of P. pastoris were submitted to appropriate inducting protocols. Expression of histidine-tagged fusion $\mathrm{N}$ proteins with a molecular mass of $54 \mathrm{kDa}$ was determined by SDS-PAGE and Western blotting analysis, confirming that both recombinant $\mathrm{N}$ proteins were comparable in size and antigenicity to native IBV N protein. The E. coli system overexpressed the recombinant $\mathrm{N}$ protein, while the $P$. pastoris system produced a low yield of this recombinant protein. The bacteria expressed $\mathrm{N}$ protein was purified by chromatography on nickel-sepharose resin. These results indicated that the pET28a E. coli expression system is more effective to generate $\mathrm{N}$ recombinant protein for using as an antigen to detect anti-IBV antibodies in immuno-assays for this viral infection.

KEY WORDS: Infectious bronchitis virus, cloning, expression, recombinant antigen, ELISA.

\section{INTRODUÇÃO}

Ovírus da bronquiteinfecciosa(VBI)é, por definição, um coronavírus de aves domésticas (espécie
Gallus gallus), esenotabiliza por seroagente etiológico dabronquite infecciosa (BI), mais comumente conhecida como bronquite infecciosa das aves. OVBIé um membro da família Coronaviridae, constituído por um 
genoma composto por um RNA de fita simples e sentido positivo com $27,6 \mathrm{~kb}$ que codifica a produção de quatro proteínas estruturais, identificadas como a glicoproteína de espícula (S), a glicoproteína integral de membrana $(\mathrm{M})$, a proteína pequena de membrana (E) e proteína fosforilada de nucleocapsídeo (N) (CAVAnagh, 2007). A proteína N do VBI, que se constituí na proteína principal do capsídeo, é produzida em grande quantidade na infecção por esse vírus. Essa proteína tem a sua estrutura altamente conservada, com cerca de 94 a 99\% deidentidadeentre as várias estirpes do VBI (WILliams et al., 1992), além de ser altamente imunogênica, sendo, por conseguinte, capaz de induzir a produção de anticorpos específicos e de linfócitos T efetores específicos, sobretudo com ação citotóxica (SNEED et al., 1989; SEO et al., 1997). Dessa forma, a proteína $\mathrm{N}$ do VBI reúne um número significativodeatributos para seconstituir noantígeno de eleição para o desenvolvimento de ensaios sorológicos a serem empregados na detecção/ mensuração de anticorpos antiantígenos de grupo desse vírus (NDIFUNA et al., 1998). As técnicas moleculares de clonagem e expressão de proteínas heterólogas em sistemas de procariotos e eucariotos são técnicas alternativas para a produção deantígenos isolados e, ainda, podem contribuir na diminuição dos custos de produção dos imunoensaios (NDIFUNA et al., 1998; LoA et al., 2004). Dentre os procedimentos de clonagem e expressão de genes codificadores de proteínas estruturais de vírus em geral e do VBI, em particular, constata-se que existem várias possibilidades já exploradas, quer seja com o uso de sistemas de hospedeiros procariotos, como a Escherichia coli (NDIFUNA et al., 1998; LOA et al., 2004; LUGOVSKAYA et al., 2006), ou eucariotos, como células de insetos transfectadas com vetores de baculovírus (GuY et al., 2002; CHEN et al., 2003). Ainda, foi demonstrado também que as leveduras Saccharomyces cerevisiae foram utilizadas na expressão da proteína $\mathrm{N}$ desse mesmo vírus (GIBERTONI et al., 2005), bem como as leveduras da espécie Pichia pastoris foram usadas para a expressão de proteínas estruturais S1 eN deum outroimportante coronavírus, o vírus da SARS (LiU et al., 2004; Lu et al., 2006). No entanto, não há informações sobre a clonagem e a expressão da proteína N do VBI nessa espécie de leveduras, nem sobre a avaliação comparativa com outros sistemas de expressão.

Assim, foi desenvolvido o presente estudo com o objetivo principal declonar expressar ogene da proteína donucleocapsídeo N da estirpeM41 do VBIem dois sistemas de expressão, constituídos por E. coli e por $P$. pastoris, e comparar o desempenho desses sistemas, no sentidodetornardisponívelessa proteína recombinante para ser utilizada como antígeno em técnicas de sorodiagnóstico da infecçãopeloVBI, ou em estudos da avaliação da imunidade contra esse vírus.

\section{MATERIALEMÉTODOS}

\section{Propagação viral e preparação do RNA}

A estirpe vacinal de referência Massachusetts 41 (M41-CNPSA - EMBRAPA - Concórdia, SC) do VBI foi propagada com base na descrição de OWEN et al. (1991). O vírus foi inoculado em ovos embrionados SPF com 9 dias de incubação, na cavidade córion-alantoide (CA), no volume de 200 $\mathrm{mL} /$ ovo. Cerca de 36 horas pós-inoculação, os ovos foram refrigerados por, no mínimo, quatro horas à temperatura de $4^{\circ} \mathrm{C}$. Em seguida, o líquido córioalantoide (LCA) foi colhido, distribuído em alíquotas e estocado a $-70^{\circ} \mathrm{C}$, a té o momento do uso. $\mathrm{O}$ ácido nucleico das amostras obtido de suspensões oriundas do LCA foi extraído com a utilização de Trizol ${ }^{\circledR}$ LS Reagent (Invitrogen ${ }^{\mathrm{TM}}$ ), de acordo com as recomendações do fabricante.

\section{Amplificação do gene N por RT-PCR}

Com base na sequência do gene da proteína $\mathrm{N}$ da estirpe M41 do VBI(“GenBank" n deacesso-M28566) foram desenhados os oligonucleotídeos (Tabela 1), de maneira a se hibridizarem com as extremidades $5^{\prime} \mathrm{e}$ 3' de toda a sequência aberta de leitura (open reading frame - orf) do gene $\mathrm{N}(1.230 \mathrm{pb})$ e possuírem sítios para clivagem com as enzimas de restrição compatíveis com a clonagem direcionada nos vetores $\mathrm{pET} 28 \mathrm{a}$ (sistema - E. coli) e pFLD (sistema - P. pastoris).

A partir do RNA viral extraído da suspensão de LCA infectado com a estirpe M41 do VBI, foi obtido o cDNA por transcrição reversa (RT), usando oligonucleotídeo randômico para, em seguida, ser amplificada pela reação em cadeia da polimerase (PCR) toda a orf do gene da proteína N, usando-se os oligonucleotídeos descritos na Tabela 1 e o kit da enzima "Platinum ${ }^{\circledR}$ Taq DNA Polymerase High Fidelity" (Invitrogen ${ }^{\mathrm{TM}}$ ), sendo as condições da PCR constituídas por um primeiro ciclo a $95^{\circ} \mathrm{C}$ por 5 minutos, seguido de outro ciclo a $70^{\circ} \mathrm{C}$ por 2 minutos e de mais 35 ciclos, cada um composto por três passos; $94^{\circ} \mathrm{C}$ por 1 minuto, para desnaturação do DNA, $48^{\circ}$ C por 1 minuto, para o hibridização dos iniciadores e $68^{\circ} \mathrm{C}$ por 2 minutos e 30 segundos, para a extensão das fitas, seguidode 10 minutos deextensão final a $68^{\circ} \mathrm{C}$. Depois da amplificação, $5 \mu \mathrm{L}$ do produto da PCR foram aplicados em gel de agarose $(0,8 \%)$ imerso em tampão TBE $0,5 x$ Tris-Borato $(0,045 \mathrm{M}), \operatorname{EDTA}(1 \mathrm{mM})$ e submetido a uma voltagem adequada às dimensões do gel (1 a 10V/cm). A visualização dos produtos amplificados, no gel de agarose, foi realizada através da transiluminação do gel em luz ultravioleta, após corá-lo em solução de brometo de etídeo $(0,5 \mu \mathrm{g} / \mathrm{mL})$ (SAMBROOK; FRITSCH; MANIATIS, 2001). 
Tabela 1 - Oligonucleotídeos utilizados para amplificação do gene N.

\begin{tabular}{lc}
\hline Oligos & Sequências de nucleotídeos \\
\hline Oligo-Pet-A+ ${ }^{*}$ & Nde I \\
Oligo-Pet-B- ${ }^{*}$ & $5^{\prime}$-GGAATTCCATATGGCAAGCGGTAAGGC-3' \\
Xho I & Xho I \\
Oligo-Pic-A+ & $5^{\prime}$-CCGCTCGAGAAGTTCATCTCTCCTAG-3' \\
Oligo-Pic-B- & $5^{\prime}$-CCGCTCGAGGTCATGGCAAGCGGTAA-3' \\
& Apa I \\
& $5^{\prime}$-ATTATTGGGCCCAAGTTCATTCTCTCCTAG-3'
\end{tabular}

*(+) senso/(-) antissenso.

\section{Clonagem do gene da proteína $\mathbf{N}$}

Os produtos amplificados contendo os insertos nas posições corretas de leitura ("in frame") - 1.249 $\mathrm{pb}$, a serem subclonados no vetor de expressão em bactérias pET-28a e o de 1.252 pb, no vetor de expressão em leveduras pFLD, foram purificados através da utilização do "kit" comercialGFXPCRDNA eGel Band Purification Kit (GE Healthcare, USA), de acordo com as especificações do fabricante, para depois serem clonados no vetor pGEM $^{\circledR}$-T Easy (Promega), o qual foi usado para a transformação de células de E. coli da linhagem DH10B, sendo que os transformantes foram cultivados em meio LB (1\% Triptona, 0,5\% Extrato de levedura, 1\% NaCl) com $50 \mu \mathrm{g} / \mathrm{mL}$ de ampicilina. Ao final dessa etapa, preparações de DNA plasmidial, obtidas a partir dos clones transformantes, foram digeridas com as enzimas Nde I e Xho I; e Xho I e Apa I, respectivamente com vistas a clonagem dessas sequências do gene $\mathrm{N}$ nos vetores pET28a ou pFLD. Os produtos dessas digestões foram analisados por eletroforese em gel de agarose. Após a extração do DNA dos clones, da verificação da presença de plasmídeos contendo o inserto do gene $\mathrm{N}$ do VBI e da determinação da quantidade de DNA, em espectrofotômetro UV, nos comprimentos de onda de $260 \mathrm{~nm}$ e $280 \mathrm{~nm}$, cada uma dessas preparações de DNA plasmidial foi submetida ao sequenciamento, utilizando os oligonucleotídeos T7 Promoter eSP6 Reverse e o kit “BigDye ${ }^{\circledR}$ Terminator" v3.1 (Perkin Elmer), para confirmar a similaridade das sequências de nucleotídeos dos genes $\mathrm{N}$ amplificados e clonados. A partir de um dos clones confirmados como portador do inserto do gene $\mathrm{N}$ da estirpe M41 do VBI, foi feita a extração do DNA plasmidial e, posteriormente, submetido à digestão com as mesmas enzimas anteriormente citadas e específicas para a clonagem direcional nos vetores de expressão, pET-28a e pFLD, que também passaram pelo mesmo processo de digestão, de forma que, ao final, as duas preparações de toda a orf do gene $\mathrm{N}$ fossem ligadas a cada um desses vetores os quais foram então usados para a transformação das células de E. coli da linhagem BL21 (DE) pLys, segundo procedimento descrito por SAMBROOK et al. (2001) e da linhagem GS115 de leveduras da espécie $P$. pastoris, tendo sido antes linearizado, o vetor $\mathrm{pFLD}$ + gene $\mathrm{N}$, com a enzima Cla I e usando-se a eletroporação, conforme recomendam os procedimentos descritos pelo fornecedor ("pFLD and pFLDá - Pichia pastoris expression vectors" - Invitrogen ${ }^{\mathrm{TM}}$ ).

Indução da expressão da proteína $\mathbf{N}$ recombinante nos clones recombinantes de E. coli

Clones transformantes da linhagem BL21 de E. coli foram selecionadose, em seguida, cultivados em $10 \mathrm{~mL}$ de meio LB contendo $100 \mu \mathrm{g} / \mathrm{mL}$ kanamicina, sob agitação de $250 \mathrm{rpm}$ a $37^{\circ} \mathrm{C}$, durante 16 horas. Em seguida, todo o volume $(10 \mathrm{~mL})$ foi transferido para $200 \mathrm{~mL}$ de meio LB contendo kanamicina na mesma concentração anterior, sendo incubado a $37^{\circ} \mathrm{C}$ sob agitação de 200 rpm. Quando a densidade óptica dessa cultura atingiu aproximadamente $0,8 \mathrm{em}$ um comprimento de onda de $600 \mathrm{~nm}$, a expressão da proteína recombinante foi induzida pela adição de IPTG (isopropil ß-D-1-tiogalactopiranosídeo) na concentração final de 0,2 mM. As culturas, depois da adição do agente de indução, foram incubadas por mais 4 horas a $30^{\circ} \mathrm{C}$ e sob agitação de $200 \mathrm{rpm}$, sendo, ao final, submetidas ao processo de extração de proteínas, conforme os procedimentos recomendados por LoA et al. (2004), exceto que a proteína recombinante foi obtida da fração solúvel e não de corpúsculos de inclusão, como no caso dos autores citados.

Indução da expressão da proteína $\mathrm{N}$ recombinante nos clones recombinantes de $P$.pastoris

Depois dos clones recombinantes de levedura terem sido selecionados após cultivo por até 2 dias a $30^{\circ}$ C em placas contendo meio YPDS (1\% extrato de 
levedura, $2 \%$ peptona, $2 \%$ glicose, $18 \%$ sorbitol, $2 \%$ ágar), contendo $100 \mu \mathrm{g} / \mathrm{mL}$ do antibiótico zeocina, foi escolhido um clone que foi submetido inicialmente a uma cultura sob a forma de um pré-inóculo em $5 \mathrm{~mL}$ demeio YPD (1\% extrato delevedura, $2 \%$ peptona, $2 \%$ glicose), mantido sob agitação de $250 \mathrm{rpm}$, a $30^{\circ} \mathrm{C}$ por 16-18 horas. Após esta etapa a cultura foi centrifugada e as células de levedura ressuspendidas em $25 \mathrm{~mL}$ de meio mínimo com glicerol: MGA (Meio mínimo com glicerole sulfato de amônio) (1,34\% Basenitrogenada de levedura sem aminoácidos, 0,02\% Biotina, 2\% Glicerol, 1\% Sulfato de amônio, 0, 004\% Histidina), onde permaneceram sob agitação por 36 horas. A indução da expressão do gene de interesse foi feita após a centrifugação e ressuspensão da cultura em 50 mL de meio MMA (Meio mínimo com metanol e sulfato de amônio) (1,34\% Basenitrogenada delevedura sem aminoácidos, 0,02\% Biotina, 1\% Metanol, 1\% Sulfato de amônio, 0,004\% Histidina) no qual permaneceu sob agitação por 96 horas, sendo adicionado metanol a cada 24 horas, em uma concentração final de $0,5 \%$.

Lise das células transformantes de $E$. coli e $P$. pastoris para extração da proteína $\mathrm{N}$ recombinante

As preparações do extrato celular para análise da produção de proteínas intracelulares recombinantes em pequena escala, em cada um dos dois sistemas de expressão utilizados neste estudo, foram coletadas por centrifugação durante 10 minutos. Os pellets celulares obtidos foram ressuspendidos em tampão de lise (50 mM Tris- $\mathrm{HCl}$, pH 7.4; 1 mM de PMSFFluoreto deFenilmetilSulfonil, $1 \mathrm{mMdeEDTA}, 1 \mathrm{mM}$ dePepstatina e 0,5 mM de Aprotinina) e, em seguida, submetidos a lise, conforme recomendam NDIFUNA et al. (1998) e GiBERTONi et al. (2005) tendo sido usado um sonicador (E. coli) (Sonics Vibra Cell - Sonics \& Materials, VC x 500) ou agitação em vórtex com esférulas de vidro (glass beads) (Sigma, St. Louis, MO) (P.pastoris). Os lisados celulares foram centrifugados a $12.000 \mathrm{xg}$ durante 10 minutos a $4^{\circ} \mathrm{C}$, tendo sido determinada de cada um desses lisados a concentração proteica, utilizando-se o método de BRADFORD (1976). Ao final, esses lisados de E. coli e de P. pastoris foram armazenados a $-20^{\circ} \mathrm{C}$ até o momento de serem analisados pelas técnicas de SDS-PAGE e Westernblotting.

Purificação da proteína $\mathrm{N}$ recombinante produzida por $E$. coli

A proteína $\mathrm{N}$ recombinante expressa em E. coli contendo 6 aminoácidos de Histidina (6xHis) foi purificada através da cromatografia de afinidade contendo a resina de níquel-sepharose ("Ni
Sepharose $^{\mathrm{TM}}$ High performance" GE Healthcare). A proteína $\mathrm{N}$ recombinante (6xHis) foi eluída com Imidazol (Sigma, St. Louis, MO). A concentração da proteína purificada foi determinada utilizando-se o Bio-Rad protein assay (Bio-Rad, Hercules, CA) baseado no método de BRADFORD (1976). As frações coletadas correspondentes aos picos de absorbância, numa concentração final da fração contendo a proteína $\mathrm{N}$ recombinante purificada de $3,4 \mathrm{mg} / \mathrm{mL}$, foram armazenadas a $-20^{\circ} \mathrm{C}$ para posterior utilização no Western-blotting.

\section{Análise por SDS-PAGE e Western blotting}

Foram seguidos, em linhas gerais, os protocolos descritos por LAEMMLI, 1970 e TOWBIN et al. (1979). Em suma, inicialmente os lisados celulares obtidos de $E$. coli ede P. pastoris submetidas ao processo de indução da expressão do gene $\mathrm{N}$, foram analisados por SDSPAGE, usando-se um sistema de tampão descontínuo. As bandas polipeptídicas separadas pela eletroforese foram detectadas em gel a $9 \%$, através da coloração utilizando o corante "Coomassie Brilliant Blue R-250. A especificidade da proteína N recombinante foi também analisada, por Western blotting, utilizando-se ou um anticorpo monoclonal anti-histidina (Sigma, St. Louis, MO), ou anticorpos policlonais anti-VBI contidos em soro de galinhas hiperimunizadas com a estirpe M41 do VBI, preparado por BRONZONI et al. (2005). Após a eletroforese, os polipeptídeos foram eletro-transferidos em cuba de transferência úmida para uma membrana de HPVDF (GE Healthcare, USA). Em seguida foram adicionados os anticorpos primários detectores; o anticorpo monoclonal anti-Histidina na diluição 1:25000, para detecção da proteína recombinante expressa em E. coli e na diluição de 1:500, para proteína expressa em $P$. pastoris, ou o soro hiperimune antiVBI na diluição de 1:500, preparada em solução salina tamponada com fosfatos ( $\mathrm{NaCl}$, $14 \mathrm{M}, 8 \mathrm{mM}$ $\mathrm{Na}_{2} \mathrm{HPO}_{4}, 2 \mathrm{mM} \mathrm{NaH}_{2} \mathrm{PO}_{4}, \mathrm{pH} 7,4$ ) acrescida de 5\% deleite em pó desnatado(PBS-LPD). Os conjugados imunoenzimáticos constituídos pela peroxidase combinada ao anticorpo de cabra anti IgG de camundongo (Bethyl Laboratories Inc.-Montomery, TX, USA), ou combinada ao anticorpo de cabra antiIgG de galinha (Bethyl Laboratories Inc. Montomery, TX, USA) foram utilizados para revelação do complexo antígeno-anticorpo, na diluição 1:500 em PBS-LPD. Após a incubação por 1h, a membrana foi novamente lavada com PBS acrescido de Tween 20 a 0,05\% e com PBS, para que a reação de desenvolvimento da cor fosse induzida após a adição da mistura do cromógeno (DiaminoBenzidina) mais substrato específico $\left(\mathrm{H}_{2} \mathrm{O}_{2}\right)$ (FAST - DAB;Sigma-Aldrich ${ }^{\circledR}$ ). 


\section{RESULTADOSEDISCUSSÃO}

Clonagem dos insertos dogene $\mathrm{N}$ da estirpe M41 do VBI nos vetores de expressão para $E$. coli e para $P$. pastoris

Foram obtidos na RT-PCR os dois produtos do gene Ncom os tamanhos esperados, istoé, de $1.249 \mathrm{pb}$ e de $1.252 \mathrm{pb}$ para cada dos dois conjuntos de iniciadores usados respectivamente para clonagem nos sistemas E. coli - pET28a e P. pastoris - pFLD. As análises por sequenciamento de nucleotídeos de 2 clones bacterianos transformados na pré-clonagem pelo vetor pGEM $^{\circledR}$-T Easy - gene N, para cada um desses sistemas, revelou que esses insertos gênicos apresentavam identidade completa com relação à sequência do gene da proteína $\mathrm{N}$ da estirpe M41 do VBI disponívelno "GenBank" sob onúmero deacesso M28566 (dados não mostrados).

No processo de clonagem desse mesmo gene no vetor pET28a, foram selecionados oito clones bacterianos dos quais dois (clones 1.1 e 2.2) foram confirmados pelas técnicas de PCR com combinação dois a dois de oligonucleotídeos (do gene $\mathrm{N}$ ou do vetor) ou por digestão com enzimas de restrição para $\mathrm{o}$ vetor contendo o inserto do gene $\mathrm{N}$ e um desses clones foi então submetido a extração do DNA plasmidial para ser usado na transformação da linhagem BL21 (DE3) pLys de E. coli, queéapropriada para a expressão de proteínas recombinantes. Desse novo ciclo de clonagem foram obtidos dois clones bacterianos, que também foram confirmados serem portadores do vetor contendo o inserto do gene $\mathrm{N}$, a fim de que fosse selecionado um clone para ser submetido ao processo de indução da expressão da proteína recombinante por esse sistema de células hospedeiras.

Para a expressão em P. pastoris, os resultados das análises do processo de subclonagem no vetor $\mathrm{pFLD}$ demonstraram que dois clones selecionados portavamoinserto do geneN que também apresentou uma completa identidade com a sequência do gene $\mathrm{N}$ da estirpe M41 do VBI ("GenBank" n 28566). Dessa forma, foi confirmado como correta a construção do inserto do gene $\mathrm{N}$ no vetor $\mathrm{pFLD}(\mathrm{pFLD}+$ gene $\mathrm{N})$, a qual foi, em seguida, escolhida para ser linearizada e depois usada para transformar as células da linhagem GS115 da levedura P. pastoris.

\section{Indução da expressão da proteína $\mathrm{N}$ recombinante no sistema $E$. coli}

Foi utilizado para expressão da proteína N recombinante produzida em pequena escala, o métodoatravés dainduçãodopromotorT7RNA polimerase pela adição de IPTG ao meio. A proteína $\mathrm{N}$ recombinante foi purificada por meio da interação coma resina "NiSepharose ${ }^{\mathrm{TM}}$ High performance" (GE Healthcare), baseado no método de BRADFORD (1976), a concentração final da fração contendo a proteína $\mathrm{N}$ recombinante purificada foi de $3,4 \mathrm{mg} / \mathrm{mL}$.

Os resultados da análise por meio de eletroforese em gel de poliacrilamida (SDS-PAGE) demonstraram a presença de um banda cujo peso molecular correspondeu a aproximadamente $54 \mathrm{kDa}$ (Fig. 1A). O mesmo ocorreu quando foi utilizado na reação de Western-blotting, o anticorpo monoclonal antihistidina, revelando uma banda intensamente marcada pelo anticorpo monoclonal, com aproximadamente $54 \mathrm{kDa}$, referente a proteína deinteresse (Fig. 1B). A concentração de proteínas totais no extrato celular obtido foi de $10 \mathrm{mg} / \mathrm{mL}$. Abaixo da banda da proteína de interesse reconhecida pelo anticorpo monoclonal, há outras bandas com tamanhos menores, que igualmente reagiram com o anticorpo monoclonal anti-histidina, parecendo se tratar de bandas da proteína $\mathrm{N}$ recombinante que sofreram alguma degradação. Porém, o anticorpo monoclonal anti-histidina não reconheceu nenhuma banda nos extratos proteicos derivados dos controles negativos constituídos somente pelo lisado de células da linhagem BL21 de E. coli.

A propósito, deve ser salientado que o tamanho molecular observado, na análise feita por meio da técnica de SDS-PAGE, para a proteína $\mathrm{N}$ recombinante produzida em E. coli, correspondeu a aproximadamente $54 \mathrm{kDa}$, que está dentro da faixa de variação esperada para a proteína de nucleocapsídeo do VBI, devendo-se considerar também, nesse caso, que há a presença adicional dos aminoácidos que compõem a cauda de poli-histidina que foi adicionada pelas sequências gênicas que codificam tais sequências de aminoácidos junto à extremidade C-terminal da proteína recombinante de fusão N. Isso faz com que a massa observada para a proteína recombinante $\mathrm{N}$ de fusão esteja no limite superior que foi reportada para a proteína viral nativa homóloga do VBI, a qual demonstrou uma variação de 51 a 54 kDa (SAIF, 1993).

Ainda, quando os anticorpos policlonais presentes no antissoro de galinha contra o VBI foram usados na técnica de Western-blotting, houve a detecção da presença de uma banda mais intensamente marcada também com $54 \mathrm{kDa}$, a qual migrou em uma posição ligeiramente acima daquela em que está localizada a proteína $\mathrm{N}$ nativa do VBI, que foi marcada pelos mesmos anticorpos e, também, de outras bandas menores que também foram marcadas intensamente (Fig. 1C). O fato de tais anticorpos produzidos em galinhas hiperimunizadas com a estirpe M41 do VBI terem apresentado reatividade cruzada com a proteína $\mathrm{N}$ recombinante produzida pela bactéria E. coli, 
confirma o elevado grau de identidade antigênica dessa proteína com a proteína $\mathrm{N}$ do próprio vírus e caracteriza também a sua identidade imunoquímica com a nucleoproteína oriunda do próprio VBI. Resultados semelhantes de avaliação da antigenicidade de preparações proteína $\mathrm{N}$ recombinante de coronavírus aviários foram obtidos por NDIFUNA et al. (1998), com o VBI e por LOA et al. (2004), com o coronavírus de perus (TCoV). Ainda, deve-se esclarecer que as bandas adicionais marcadas pelos anticorpos policlonais de galinha e com tamanhos menores, provavelmente se tratam de frações proteicas da própria E. coli, já que as aves são SPF, mas não são livres de contato com a E. coli.

\section{Indução da expressão da proteína $\mathrm{N}$ recombinante no sistema $P$. pastoris}

A indução da expressão pelo sistema pFLD - $P$. pastoris foi realizada sobre os clones da linhagem GS115 dessa levedura transformada, através da eletroporação, com a construção do inserto do geneN no vetor $\mathrm{pFLD}$ sob a forma linearizada pela a enzima Cla I. Dentre esses clones, foi escolhido um para a indução da expressão, em pequena escala da proteína N recombinante do VBI nesse sistema. Decorridas 96 horas após a introdução do metanol, que é o agente indutor de expressão, o extrato de proteínas totais foi obtido através da lise do sedimento de células previamente separadas por centrifugação, bem como foi testada uma alíquota do sobrenadante, tendo sido obtida apenas do primeiro extrato, istoé, no compartimento intracelular, uma concentração muito reduzida de proteínas totais e igual a $0,250 \mathrm{mg} / \mathrm{mL}$, queao ser analisado por SDS-PAGE (Fig. 2A) e no Western blotting, utilizando o anticorpo monoclonal antihistidina (Fig. 2B), revelou a presença de uma banda fracamente marcada e com um tamanho aproximado de $54 \mathrm{kDa}$. Ainda, deve ser enfatizado que o extrato proteico obtido de células da mesma linhagem dessa levedura transformadas com o vetor sem o inserto do gene N não apresentou nenhuma marcação com esse mesmo anticorpo monoclonal. Estes resultados demonstram que houve uma baixa eficiência na produção, em pequena escala, da proteína $\mathrm{N}$ recombinante do VBI pelo sistema vetor pFLD na linhagem GS115 de $P$. pastoris, o que inviabilizou a caracterização imunoquímica complementar e a purificação dessa proteína em resina de afinidade, tal como foi feito com a proteína N recombinante produzida pelo sistema de expressão constituído pela E. coli.

Com respeito às dificuldades verificadas na expressão da proteína $\mathrm{N}$ do VBI pelo sistema P. pastoris, deve ser lembrado que uma eficiência muito baixa para expressão de proteína recombinante heteróloga foi relatada na tentativa de produção da proteína S1 recombinante de outro coronavírus, o vírus daSARS, pelosistema combinando o vetor $\mathrm{PPIC9K}-$ P. pastoris, sobretudo quando se fez a comparação com osistema constituído por células hospedeiras da linhagem BL21 de E. coli (Lu et al., 2006). A razão para esse insucesso foi vinculada por esses autores à presença de regiões abundantes $\mathrm{A}+\mathrm{T}$ na sequência do gene de interesse a ser clonado e expresso, a qual funciona como alça de poliadenilação em P. pastoris, resultando em terminação não apropriada do processo de transcrição do gene da proteína heteróloga recombinante. Há, então, que se levar em conta que no mínimo esta condição possui algo em comum com os resultados de nosso trabalho e pode ser uma das prováveis causas do insucesso na expressão da proteína $\mathrm{N}$ do VBI pelo sistema P. pastoris, empregado em nosso estudo.

Por outro lado, deve ser considerado também que a proteína $\mathrm{N}$ do coronavírus da SARS, que é uma proteína heteróloga análoga à proteína $\mathrm{N}$ do $\mathrm{VBI}$, foi expressa de forma bem sucedida e em quantidades significativas pelo sistema constituído pelo vetor pPIC3,5K-P.pastoris, sendoqueo processodeindução também foi realizado em escala pequena e usando-se frascos do tipo Erlenmeyer em incubadoras com agitação orbital (LuU et al., 2004), tal como foi em grande parteempregadononosso estudo. Deveseressaltado, entretanto, que o vetor escolhido na investigação acima foi diferente daquele que foi utilizado por nós e, em adição a isso, os autores avaliaram diferentes meios de cultura, tanto na fase de pré-indução, como deindução, bem como as condições ideais deaeração, de $\mathrm{pH}$ e da concentração de manutenção do agente indutor, o metanol, enquanto que, em nosso estudo, foi seguido um protocolo básico recomendado pelo fornecedor do vetor ("pFLD and pFLDá - P. pastoris expression vectors" - Invitrogen $\left.{ }^{\mathrm{TM}}\right)$.

A propósito, deve ser ressaltadoneste ponto quea escolha feita em nosso trabalho pelo vetor pFLD deuse em razão de este vetor incluir sequências de nucleotídeos extras para permitir a expressão da proteína heteróloga como uma cauda de poli-histidina, com vistas a facilitar o processo de detecção e de purificação depois de expressar tal proteína recombinante. Além disso, podem ser levantadas suspeitas sobre a não adequação do vetor $\mathrm{pFLD} \mathrm{com}$ a linhagem GS115 de P. pastoris, embora não haja nenhuma recomendação em contrário nas diretrizes dos protocolos para clonagem e expressão de proteínas heterólogas recombinantes por tal vetor ("pFLD and pFLDá - P. pastoris expression vectors" Invitrogen $\left.^{\mathrm{TM}}\right)$. Fica, nesse caso, a dúvida, que poderia ser dirimida e investigada no futuro; por exemplo, tentando se fazer uma nova construção do inserto do gene $\mathrm{N}$ do VBI no vetor pPIC para ser usado na transformação de células da mesma linhagem GS115 de P. pastoris. 


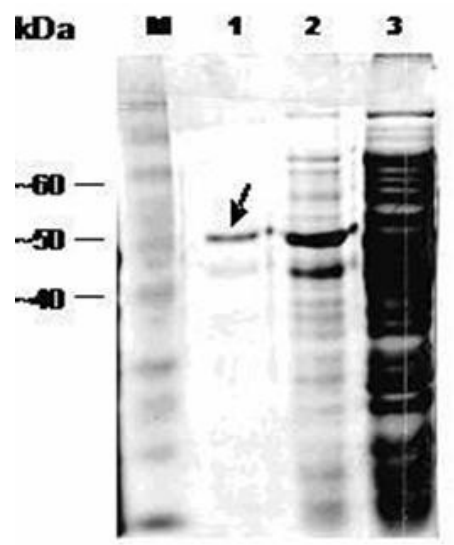

A

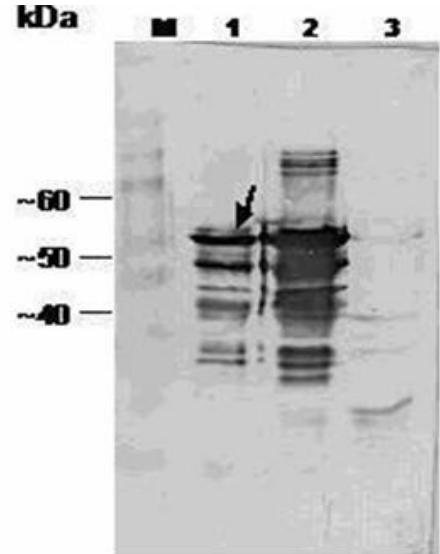

B

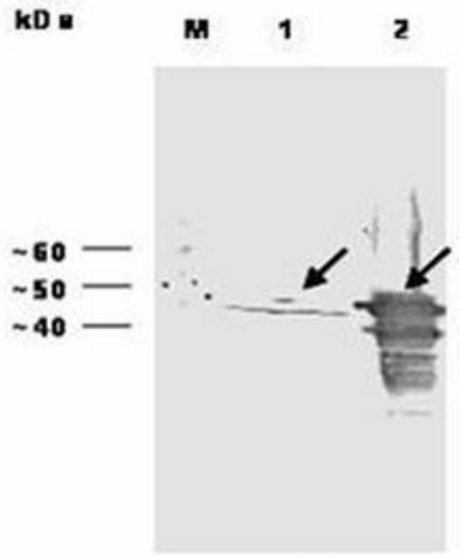

C

Fig. 1 - Análise nas técnicas de SDS-PAGE (A) e de Western-blotting com anticorpos detectores monoclonais anti-His (B) ou policlonais anti-VBI (C). Fração purificada da proteína recombinante N da estirpe M41 do VBI expressa em E. coli utilizando o anticorpo monoclonal anti-histidina (A e B) e interação da proteína N recombinante do VBI expressa em E. coli com anticorpos policlonais presentes no soro de galinhas hiperimunizadas com a estirpe M41 desse vírus (C). As amostras correspondem, respectivamente; Canaletas: (M) Marcador de Peso Molecular, (Bench Marck - Invitrogen), (A e B) (1) Proteína recombinante do nucleocapsídeo da estirpe M41, expressa em E. coli, purificada por eluição da resina de Níquel-sepharose.(2) Extrato bruto de proteínas de células transformadas de E. coli com o gene N da estirpe M41 (3) Extrato bruto de proteínas de células transformadas de E. coli somente com o vetor pET28a. A seta indica a banda correspondente da proteína $\mathrm{N}$ recombinante do VBI ( $\cong 54 \mathrm{KDa})$. (C) (2) Extrato de E. coli transformada pelo vetor pET28a com o inserto do gene N da estirpe M41 do VBI. As setas indicam a marcação da banda correspondente à proteína N da suspensão concentrada do VBI ou a proteína N recombinante presente no extrato proteico bruto de E. coli transformada pelo vetor pET28a mais o inserto do gene $\mathrm{N}$. As setas indicam ou a proteína $\mathrm{N}$ do próprio VBI (canaleta 1 ) ou a proteína $\mathrm{N}$ recombinante (canaleta 2 ).

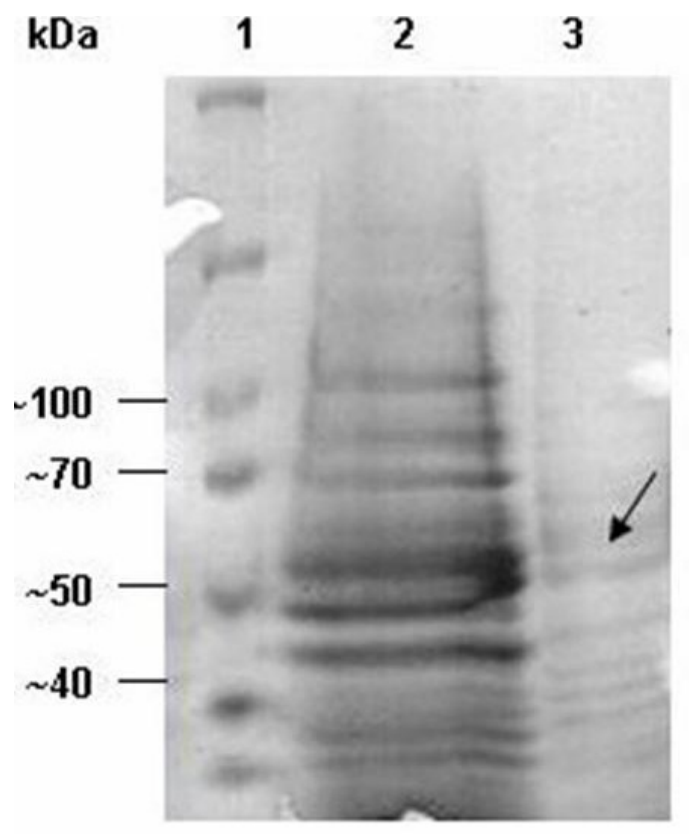

A

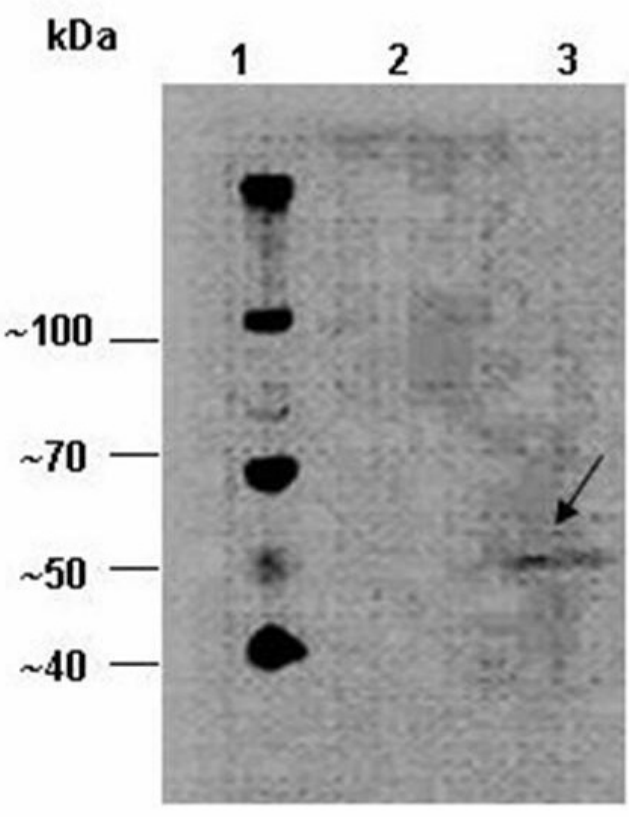

B

Fig. 2 - Análise pelas técnicas de (SDS-PAGE) (A) e Western-blotting (B) da fração bruta da proteína recombinante N da estirpe M41 do VBI expressa em P. pastoris, utilizando o anticorpo monoclonal anti-histidina. As amostras correspondem, respectivamente; Linha 1, Marcador de peso molcular de proteínas Spectra Multicolor Broad Range Protein Ladder (Fermentas), Linha 2, extrato bruto de proteínas de células transformadas de $P$. pastoris somente com o vetor pFLD, Linha 3, extrato bruto de proteínas de células transformadas de $P$. pastoris com o vetor $\mathrm{pFLD}+\mathrm{o}$ inserto do gene $\mathrm{N}$ da estirpe M41 do VBI. A seta indica a banda correspondente da proteína N recombinante do VBI ( 54 KDa). 
Concluindo, o sistema pET28a-E.coliapresentou, em nosso estudo, um conjunto considerável de vantagens em relação ao sistema de expressão constituído por $\mathrm{pFLD}$ - P.pastoris para a expressão da proteína $\mathrm{N}$ recombinante a qual tem um grande potencial para ser utilizada de forma bem sucedida no sorodiagnóstico ou em investigações sobre o imunodiagnóstico da bronquite infecciosa.

\section{AGRADECIMENTOS}

Este estudo foi financiado pela Fundação de Amparoà Pesquisa deSão Paulo,(Processos números 05/54275-4 e 01/14650-3), ao Conselho Nacional de Pesquisa CNPq (proc. 477140/2003-3) e à Empresa MERIAL Saúde Animal.

\section{REFERÊNCIAS}

BRADFORD, M.M. A rapid and sensitive method for the quantitation of microgram quantities of protein utilizing the principle of protein-dye binding.

Analytical Biochemistry, v.72, p.248-254, 1976.

BRONZONI, R.V.M.; MONTASSIER, M.F.S.; PEREIRA, G.T.; GAMA, N.M.S.Q.; SAKAI, V.; MONTASSIER, H.J. Detection of infectious bronchitis virus and specific anti-viral antibodies using a concanavalin ASandwich-ELISA. Viral Immunology, v.18, n.3, p.569-578, 2005.

CAVANAGH, D. Coronavirus avian infectious bronchitis vírus. Veterinary Research, v.38, n.22, p.281297, 2007.

CHEN, H.; COOTE, B.; HISCOX, J.A. Evaluation of a nucleoprotein-based enzyme-linked immunosorbent assay for the detection of antibodies against infectious bronchitis virus. Avian Pathology, v.32, n.5, p.519-526, 2003.

GIBERTONI, A.M.; MONTASSIER, M.F.; SENA, J.A.; GIVISIEZ, P.E.; FURUYAMA, C.R.; MONTASSIER, H.J. Development and Application of a Saccharomyces cerevisiae-Expressed Nucleocapsid Protein-Based Enzime-Linked Immunosorbent Assay for Detection of Antbodies against Infectious Bronchitis Virus. Journal of Clinical Microbiology, v.43, n.4, p.1982-1984, 2005.

GUY, J.S.; SMITH, L.G.; BRESLIN, J.J.; PAKPINYO, S. Development of a competitive enzime-linked immunosorbent assay for detection of turkey coronavirus antibodies. Avian Diseases, v.46, n.2, p.334341,2002

LAEMMLI, U.K. Cleavage of strutural proteins during assembly of the head of $\mathrm{T}_{4}$ bacteriophage. Nature, v.227, p.680-681, 1970.
LIU, R.S.; YANG, K.Y. LIN, J.; LIN, Y.W.; ZHANG, Z.H.; ZHANG, J.; XIA, N.S. 15 High-yield expression of recombinant SARS Coronavirus nucleocapsid protein in 16 methylotrophic yeast Pichia pastoris. World Journal of Gastroenterology, v.10, n.17/24, p.36023607, 2004.

LOA, C.C.; LIN, T.L.; WU, C.C.; BRYAN, T.A.; HOOPER, T.; SCHRADER, D. Expression and purification of turkey coronavirus nucleocapsid protein in Escherichia coli. Journal Virological Methods, v.116, p.161-167, 2004.

LU, H.; YANG, G.; FEI, X.; GUO, H.; TAN, Y.; CHEN, H.; GUO, A. Modification of SARS-CoV S1 gene render expression in Pichia pastoris. Virus Genes, v.33, p.329335, 2006.

LUGOVSKAYA, V.V.; SCHERBAKOV, A.V.; YAKOVLEVA, A.S.; TSYVANYUK, M.A.; MUDRAK, N.S.; DRYGIN, V.V.; BORISOV, A.V. Detection of antibodies to avian infectious bronchitis virus by a recombinant nucleocapsid protein-based enzymelinked immunosorbent assay. Journal Virological Methods, v.135, p.292-296, 2006.

NDIFUNA, A.; WATERS, A.K.; ZHOU, M.; COLLISSON, E.W. Recombinant nucleocapsid protein is potencially an inexpensive, effective serodiagnostic reagent for infectious bronchitis virus. Journal Virological Methods, v.70, p.37-44, 1998.

OWEN, R.L.; COWEN, B.S.; HATTEL, A.L.; NAQI, S.A.; WILSON, R.A. Detection of viral antigen following exposure of one-day-old chickens to the Holland-52 strain of IBV. Avian Pathology, v.20, n.4, p.663-673, 1991.

SAIF, L.J. Coronavirus immunogens. Veterinary Microbiology, v.37, p.285-297, 1993

SAMBROOK, J.; FRISTSCH, E.F.; MANIATIS, T. Molecular cloning: a laboratory manual. 3.ed. New York: Cold Spring Harbor Laboratory, 2001.

SEO, S.H.; WANG, H.L.; SMITH, R.; COLLISON, E.W. The carboxyl-terminal 120-residue polypeptide of infectious bronchitis virus nucleocapside induces cytotoxic T lymphocytes and protects chicken from acute infection. Journal of Virology, v.71, n.10, p.78897894, 1997.

SNEED, L.W.; BUTCHER, G.D.; PARR, R.; WANG, L.; COLLISSON, E.W. Comparisons of the structural proteins of avian bronchitis virus as determined by Western-Blotting analysis. Viral Immunology, v.2, p.221227, 1989.

TOWBIN, H.T. STAEHETIN, A.; GORDON, J.

Eletrophoretic transfer of protein from polyacrylamide gels to nitrocellulose sheets: Produce 
and some applications. Proceedings of the National Academy of Sciences, of the United State of America, v.76, n.9, p.4350-4354, 1979.

WILLIAMS, A.K.; WANG, L.; SNEED, L.W.; COLLISON, E.W. Comparative analysis of the nucleocapsid genes of several strains of infectious bronchitis viruses and other coronaviruses. Virus Research, v.25, n.3, p.213$222,1992$.

Recebido em 18/2/09

Aceito em 9/10/09 